\title{
CRIMES DE ECOCÍDIO NA FLORESTA AMAZÔNICA: O PACTO ECOLÓGICO EUROPEU COMO UMA ALTERNATIVA CONTRA CRIMES AMBIENTAIS
}

\author{
Daiana Dalla Vecchia ${ }^{1}$ \\ Amanda Moura da Costa ${ }^{2}$ \\ Fernanda Assunção Conceição ${ }^{3}$
}

\section{RESUMO}

Objetivo do estudo: $O$ artigo científico objetivou analisar os desmatamentos e queimadas ocorridas na floresta amazônica nos últimos anos, desde o início do mandato do atual governo federal, aqui entendidos como crimes contra a humanidade e como o Pacto Ecológico Europeu poderá influenciar essa realidade.

Metodologia: Efetuou-se uma revisão bibliográfica em artigos científicos e livros que tratassem da questão dos crimes de ecocídio no Brasil e a competência do Tribunal Penal Internacional para julgar tais crimes, alinhado aos estudos sobre o Pacto Ecológico Europeu, além do levantamento de dados estatísticos.

Originalidade/Relevância: Esta pesquisa parte do pressuposto de que o Pacto Ecológico Europeu poderá impactar positivamente para uma mudança climática e socioambiental no Brasil, se tornando uma maneira de enfrentamento aos crimes de ecocídio ocorridos na amazônia nos últimos anos.

Principais resultados: A pesquisa observou como as queimadas e os desmatamentos na Amazônia se enquadram dentro do conceito de ecocídio e como o Tribunal Penal Internacional aborda e atua diante do tema. O estudo concluiu, que a falta de tipificação do crime impossibilita a sua responsabilização seja no âmbito nacional ou internacional, razão pela qual foi observado como políticas do Pacto Ecológico Europeu podem ser favoráveis para a situação ambiental brasileira atual.

Contribuições teóricas: A pesquisa contribui demonstrar a necessidade de uma tipificação do crime de ecocídio a fim de barrar a degradação ambiental no país. Além disso, o estudo relevou que o Pacto Ecológico Europeu possui ferramentas auxiliadoras para que o Brasil, através da pressão externa, corrija suas políticas ambientais.

Palavras-chave: Crimes ambientais. Ecocídio. Floresta Amazônica. Pacto Ecológico Europeu.

Submetido em: 03/01/2021

Aprovado em: 22/05/2021

DOI: https://doi.org/10.37497/revcampojur.v9i2.737

\footnotetext{
${ }^{1}$ Doutora em Economia, Universidade Federal da Bahia - UFBA, Bahia, (Brasil). Professora nos cursos de Administração e Ciência Contábeis na Faculdade Lusófona, São Paulo. E-mail: daianadvacchia@ hotmail.com Orcid https://orcid.org/0000-0002-0556-8821

${ }^{2}$ Mestranda em Direitos Humanos, Universidade do Minho, Portugal (Uminho). Membro do grupo de pesquisa Direito e Sexualidade, Universidade Federal da Bahia - UFBA, Bahia, (Brasil). E-mail: amandamourac@hotmail.com Orcid https://orcid.org/0000-0001-6555-3587

${ }^{3}$ Pós-graduanda em Direito Empresarial pela Faculdade Legale, São Paulo, (Brasil). Especialista em Direito Empresarial, Faculdade Legale; Membro do grupo de pesquisa Direito e Sexualidade, Universidade Federal da Bahia - UFBA, Bahia, (Brasil). E-mail: advfcassuncao@gmail.com Orcid https://orcid.org/0000-0002-5368-0180
} 


\title{
ECOCIDE CRIMES IN THE AMAZON RAINFOREST: THE EUROPEAN ECOLOGICAL PACT AS AN ALTERNATIVE AGAINST ENVIRONMENTAL CRIMES
}

\begin{abstract}
Objective of the study: The scientific article aimed to analyze the deforestation and fires that have occurred in the Amazon rainforest in recent years, since the beginning of the mandate of the current federal government, here understood as crimes against humanity and how the European Ecological Pact can influence this reality.
\end{abstract}

Methodology: A bibliographic review was made of scientific articles and books dealing with the issue of ecocide crimes in Brazil and the competence of the International Criminal Court to judge such crimes, aligned with studies on the European Ecological Pact, in addition to a survey of statistical data.

Originality/Relevance: This research starts from the assumption that the European Ecological Pact could positively impact for a climatic and socio-environmental change in Brazil, becoming a way to confront the ecocide crimes occurred in the Amazon in recent years.

Main results: The research observed how the burning and deforestation in the Amazon fit within the concept of ecocide and how the International Criminal Court approaches and acts in the face of the issue. The study concluded, that the lack of typification of the crime makes it impossible to hold it accountable either nationally or internationally, which is why it was observed how European Ecological Pact policies can be favorable for the current Brazilian environmental situation.

Theoretical contributions: The research contributes to demonstrate the need for a typification of the crime of ecocide in order to bar environmental degradation in the country. Furthermore, the study revealed that the European Ecological Pact has auxiliary tools for Brazil, through external pressure, to correct its environmental policies.

Keywords: Environmental crimes. Ecocide. Amazon Forest. European Green Deal.

\section{INTRODUÇÃO}

Os desmatamentos, assim como as queimadas, ocorrem em todas as partes do mundo, muitas vezes oriundas da própria ação natural e das características climáticas de um determinado local. A floresta amazônica no Brasil, desde muito tempo vem sofrendo com severas ações de queimadas e desmatamentos que não são causadas pela ação natural. No ano de 2019 as gravidades se tornaram muito maiores, pois desde que iniciou o mandato do atual presidente Jair Bolsonaro, o qual se mostra anti ambiental, havendo um exponencial aumento nas queimadas e nos desmatamentos da floresta. Institutos de pesquisas ambientais indicam que houve em 2019 um aumento de 44\% do desmatamento no território comparado ao ano de 2018, 
além de um registro de 32.728 focos de incêndio na floresta, causando grande preocupação para a sociedade brasileira e também internacional.

É neste contexto de crescente desmatamento e queimadas dos últimos anos que, tanto no Brasil quanto na sociedade internacional, passou-se a discutir com mais ênfase as questões ambientais como sendo crimes de ecocídio, que nada mais é do que a destruição massiva de um ecossistema, causando a morte de comunidades animais, vegetais e também interferindo negativamente na vida humana. Dessa forma, o presente artigo irá analisar o conceito do crime de ecocídio, e como, após muita movimentação de ambientalistas e juristas, o Tribunal Penal Internacional, competente para julgar graves crimes contra a humanidade, atua sobre o tema e elaborou um documento que poderá ser o primeiro passo para uma possível edificação da tipificação do crime dentro do direito internacional.

A partir desse conceito de ecocídio, a pesquisa irá demonstrar como os crimes ambientais ocorridos na floresta amazônica desde o ano de 2019 se enquadram no conceito do referido crime e analisará como as condutas de políticas ambientais do atual governo foram prejudiciais ao meio ambiente e favoráveis para o aumento de crimes, além de verificar como as ações do governo durante a pandemia da Covid19, no tocante aos povos indígenas, ajudam a comprovar que as ações atuais no Brasil contribuem para o crime de ecocídio.

Por fim, a pesquisa investigará como o Pacto Ecológico Europeu, ou o também conhecido European Green Deal, medida adotada pela União Europeia para proteção do meio ambiente e melhoria da qualidade de vida dos europeus, ajudará no combate ao ecocídio brasileiro, já que as políticas adotas pelo Bloco poderão impactar significativamente as relações comerciais entre Brasil e União Europeia, fazendo com que o país reveja seus planos de medidas ambientais preservando o ecossistema e a vida humana.

METODOLOGIA ADOTADA: Na esteira dessa análise, o presente artigo pretende questionar a necessidade da tipificação do crime de ecocídio e como as estratégias europeias, a exemplo do Pacto Ecológico Europeu, podem ajudar na proteção ambiental e, também, da vida humana, no território brasileiro. Para a elaboração do presente estudo foram levantadas pesquisas de revisões bibliográficas em artigos científicos e livros, os quais abordam o tema central sobre o crime de ecocídio e a competência do Tribunal Penal Internacional para julgar tal crime, além de dados estatísticos que revelaram mudanças expressivas no número de casos de crimes ambientais na Amazônia, particularmente nos últimos anos sob o comando do atual governo federal, alinhado aos estudos sobre o Pacto Ecológico Europeu, estratégia criada pelo Parlamento Europeu em 2020, que visa impactar não somente a União Europeia, como todos os parceiros econômicos do bloco. 


\section{ECOCÍDIO E O TRIBUNAL PENAL INTERNACIONAL}

O aumento das atividades humanas e a exponente exploração de recursos naturais, muitas vezes justificadas pelo desenvolvimento econômico, trazem consigo grandes impactos ambientais e para a vida humana, já que o aumento da poluição, desmatamentos, queimadas e as consequentes mudanças climáticas alteram não só a fauna e flora, mas também o que representa para a sobrevivência humana. Os impactos ambientais causados pelo homem, interferem diretamente na vida humana, já que somos dependentes dos recursos naturais para vivermos, de modo que, as ações exageradas e ilícitas são altamente prejudiciais à biodiversidade e para o homem. Muitas das atividades ambientais ilícitas têm a sua origem em empresas de capital internacional, o que dificulta a atuação do direito internacional para dar soluções ao problema (MARTIN-CHENUT; NEYRET; PERRUSO, 2015), no entanto, a preocupação com a destruição do meio ambiente está cada vez mais ganhando terreno nos países e na comunidade internacional.

No sentido de uma urgente necessidade de rever as ações humanas e as ações da economia internacional, que os crimes ambientais vêm ganhando um forte reconhecimento no campo do direito internacional, colocando em questão uma nova visão de vida entre o homem e o meio ambiente. Assim, as comunidades internacionais, preocupadas com os crimes ambientais que ameaçavam a vida humana, já cogitavam desde 1970, em uma Conferência sediada em Washington, instituir o termo ecocídio em uma nova Convenção, dando o significado ao termo como sendo uma referência ao genocídio, o qual, transferido para a perspectiva ambiental, nada mais é do que a destruição do ecossistema em tempos de guerra ou não (MARTIN-CHENUT; NEYRET; PERRUSO, 2015).

A sociedade internacional em 1972 realizou a Conferência das Nações Unidas sobre o Meio Ambiente Humano, em Estocolmo, que é um dos marcos para o direito ambiental, o qual trouxe ao terreno a consciência universal sobre a proteção ambiental, quando reconhece que "O homem tem o dever solene de proteger e melhorar o meio ambiente para as gerações presentes e futuras" (PRADO, 2019), constituindo uma nova visão do mundo para com o ambiente, de forma que o ambiente precisava de uma atenção especial por todas as sociedades, passando a ganhar um sentido universal.

Com o passar dos anos, ambientalistas, ativistas, acadêmicos e as comunidades internacionais, inspirados no aparecimento do termo em 1970 e na Convenção de Estocolmo, definiram o ecocídio como sendo "o dano extensivo, a perda do ecossistema de um determinado território, seja pela atuação humana ou por outras causas" (HIGGINS, 2012), na tentativa de 
que o crime fosse previsto nos instrumentos internacionais, a fim de responsabilizar os agentes de crimes ilegais contra o meio ambiente, já que a falta de equilíbrio ecológico da biosfera, oriundas das relações do homem com o ambiente, vem causando grande impacto na vida ambiental e humana.

Ocorre que, mesmo com a urgência do assunto em vista dos problemas ambientais em todo o mundo, o ecocídio ainda não é um crime tipificado perante os instrumentos de direito internacional. No entanto, diante de todas as preocupações em volta do ambiente, no ano de 2016 o Tribunal Penal Internacional (TPI), o qual é uma instituição internacional permanente, com jurisdição complementar aos tribunais nacionais para julgar indivíduos responsáveis pelos crimes de maior gravidade com alcance internacional, como a exemplo do genocídio ${ }^{4}$ e crimes contra a humanidade ${ }^{5}$, elaborou, através da sua procuradoria, um documento, intitulado como Policy paper on case selection and prioritisation ( INTERNATIONAL CRIMINAL COURT, 2016), estabelecendo a prioridade de julgamento de casos, levando em consideração a gravidade do crime, o grau de responsabilidade dos agentes, a natureza do crime e os impactos causados por eles.

\footnotetext{
${ }^{4}$ Ao abrigo do Estatuto de Roma, que regula o Tribunal Penal Internacional, o artigo $6^{\circ}$ estabelece - Para os efeitos do presente Estatuto, entende-se por «genocídio» qualquer um dos actos que a seguir se enumeram, praticado com intenção de destruir, no todo ou em parte, um grupo nacional, étnico, rácico ou religioso, enquanto tal: a) Homicídio de membros do grupo;

b) Ofensas graves à integridade física ou mental de membros do grupo;

c) Sujeição intencional do grupo a condições de vida pensadas para provocar a sua destruição física, total ou parcial;

d) Imposição de medidas destinadas a impedir nascimentos no seio do grupo;

e) Transferência, à força, de crianças do grupo para outro grupo.

5 Artigo $7^{\circ}$ do TPI estabelece - 1 - Para os efeitos do presente Estatuto, entende-se por «crime contra a Humanidade» qualquer um dos actos seguintes, quando cometido no quadro de um ataque, generalizado ou sistemático, contra qualquer população civil, havendo conhecimento desse ataque:

a) Homicídio;

b) Extermínio;

c) Escravidão;

d) Deportação ou transferência à força de uma população;

e) Prisão ou outra forma de privação da liberdade física grave, em violação das normas fundamentais do direito internacional;

f) Tortura;

g) Violação, escravatura sexual, prostituição forçada, gravidez à força, esterilização à força ou qualquer outra forma de violência no campo sexual de gravidade comparável;

h) Perseguição de um grupo ou colectividade que possa ser identificado, por motivos políticos, raciais, nacionais, étnicos, culturais, religiosos ou de sexo, tal como definido no n. ${ }^{\circ} 3$, ou em função de outros critérios universalmente reconhecidos como inaceitáveis em direito internacional, relacionados com qualquer acto referido neste número ou com qualquer crime da competência do Tribunal;

i) Desaparecimento forçado de pessoas;

j) Crime de apartheid;

k) Outros actos desumanos de carácter semelhante que causem intencionalmente grande sofrimento, ferimentos graves ou afectem a saúde mental ou física.
} 
Além disso, ao abrigo do parágrafo 41 do referido documento, ficou estabelecido que os crimes de destruição do ambiente e a exploração ilegal de recursos naturais serão dadas atenção especial pelo TPI, levados a similaridade de julgamento dos crimes contra a humanidade, já previstos no Estatuto. Assim, o documento produzido é pioneiro e importante no contexto, uma vez interpreta o alargamento do crime contra a humanidade, de modo que a avaliação da gravidade de um crime e seus eventuais danos causados ao meio ambiente podem ser julgados pelo Tribunal Penal Internacional, sendo assim, um crime ambiental comparado a um crime contra a humanidade.

Com isso, em que pese o TPI não tenha tipificado o crime ou ainda não tenha julgado crimes de ecocídio, o Policy paper on case selection and prioritisation tem papel fundamental no campo jurídico e político internacional, a fim de que os tratamentos de crimes ao meio ambiente sejam reconhecidos, admitindo a necessidade de garantir uma proteção criminal no tocante à destruição ambiental (MISTURA, 2018), sendo um fundamental instrumento pioneiro na tentativa de edificar a tipificação do crime de ecocídio internacionalmente, fato que vem, cada vez mais, ganhando força no cenário internacional.

\subsection{ECOCÍDIO NO BRASIL: DESMATAMENTOS E QUEIMADAS NA FLORESTA AMAZÔNICA}

A Constituição Federal Brasileira de 1988 alargou a definição do que vem a ser o conceito de meio ambiente, estabelecendo, ao abrigo do artigo $225 .^{\circ}$ :

Todos têm direito ao meio ambiente ecologicamente equilibrado, bem de uso comum do povo e essencial à sadia qualidade de vida, impondo-se ao Poder Público e à coletividade o dever de defendê-lo e preservá-lo para as presentes e futuras gerações (BRASIL, 1988).

Assim, é possível entender que a ampla definição do que é o meio ambiente na Carta Magna trouxe indicativos importantes, tendo o ponto em maior destaque que o destinatário do direito ambiental é a pessoa humana, ou seja, o meio ambiente está diretamente relacionado ao princípio da dignidade da pessoa humana (FIORILLO; CONTE, 2012), em razão da relação íntima entre natureza e sociedade, assim, o direito ao ambiente equilibrado nada mais é do que um direito fundamental. Nesse enquadramento alargado, o meio ambiente está intrinsecamente unido ao bem-estar de todos, onde a fauna, flora e o homem devem viver em equilíbrio e harmonia para o desenvolvimento nacional, devendo os titulares do meio ambiental a função de protegê-lo e preservá-lo em conjunto com o poder público, pois, segundo a norma, um ambiente ecologicamente equilibrado é um direito de todos (RODRIGUES, 2018), assim há 
uma correlação estreita com os valores de dignidade, liberdade, igualdade da justiça (artigo 5. ${ }^{\circ}$ da $\mathrm{CF}$ ) e com os direitos fundamentais (artigo 3. ${ }^{\circ}$ da $\mathrm{CF}$ ), “já que não é possível agora falar em qualidade de vida humana sem uma conservação adequada do meio ambiente. Ou seja: a própria existência da espécie humana depende dessa proteção" (PRADO, 2019).

Após isso, muitas outras legislações infraconstitucionais foram surgindo no Brasil para proteger o meio ambiente, o que levou ao país em um vasto acervo legislativo, em razão da necessidade da proteção ambiental, muitos, inclusive, rodeados de críticas sobre a atuação efetivas dessas leis. Dentre elas estão a Lei de Crimes Ambientais no 9.605/1998 a qual estabeleceu a aplicação de pena para crimes do ambiente e o Novo Código Florestal criado pela Lei $n^{\circ} 12.651 / 2012$, o qual define em seu artigo $3^{\circ}$ a importância da Reserva Legal ${ }^{6}$, que nada mais é do que uma área de imóvel rural, coberta por vegetação natural, que pode ser explorada com o manejo florestal sustentável nos limites estabelecidos pela lei, além de prever as dispensas para a reserva legal. O governo criou, também, a Lei número 9.985/2000 do Sistema Nacional de Unidades de Conservação, Snuc, que protege áreas de conservação da floresta que não podem ser desmatadas e queimadas, e que devem atender um sistema sustentável e controlado.

Ao abrigo do artigo $50^{\circ}$ da Lei de Crimes Ambientais, o legislador condena penalmente quem derrubar grande quantidade das árvores, desfazer, degradar ou destruir a floresta, plantada ou nativa, em terras de domínio publico ou devolutas, sem qualquer autorização, a reclusão de 2 ou 4 anos e multa. Contudo, já o Novo Código Florestal, em seu artigo $40^{\circ}$, o legislador trata com ponderação os desmatamentos ilegais acontecidos antes de 2008 convertendo a sanção em multa, ademais, no artigo $51^{\circ}$ do mesmo código, o legislador tentou criar um controle de desmatamento, onde o Poder Público, verificando a existência de ilícito ambiental, deverá impedir a continuidade do dano ambiental, no entanto, o referido artigo demonstra muito mais a preocupação da atuação do limite do Poder Público, do que em controlar verdadeiramente o desmatamento ambiental, nos fazendo notar que, mesmo com uma vasta malha normativa referente ao assunto o legislador brasileiro continua tendo poucas atuações efetivas no terreno (RODRIGUES, 2018).

Mesmo com todas as legislações sobre o tema ambiental, percebe-se dos dados do Instituto de Pesquisa Ambiental da Amazônia (IPAM) que o desmatamento no Brasil tem

\footnotetext{
${ }^{6}$ Artigo $3^{\circ}(\ldots)$ III - Reserva Legal: área localizada no interior de uma propriedade ou posse rural, delimitada nos termos do art. 12, com a função de assegurar o uso econômico de modo sustentável dos recursos naturais do imóvel rural, auxiliar a conservação e a reabilitação dos processos ecológicos e promover a conservação da biodiversidade, bem como o abrigo e a proteção de fauna silvestre e da flora nativa;
} 
crescido exponencialmente, em particular durante os anos de 2018 e 2019, sendo que muitos desses desmatamentos ocorreram em áreas de Conservação e, também, "em áreas nãodesignada e sem informação", de acordo com o Instituto, os desmatamentos somados com os ocorridos em áreas de conservação, chegam a um aumento de $44 \%$ no ano de 2019. Além disso, o IPAM reconhece que a prática da grilagem de terras é, ainda, uma das ações que ajudam a dilapidar as florestas amazônicas, e mesmo com a atuação da Snuc e outras leis de Reserva Ambiental, os ruralistas continuam colocando fogo em áreas de proteção ou áreas não identificadas, com o intuito de ampliar a fronteira agrícola, colocam seus gados ou suas plantações, e fazem parecer que não é um desmatamento ilegal (IPAM, 2019).

Além da prática da grilagem, das plantações de soja em terras ilícitas, a floresta amazônica sofre, desde sempre, com a extração da madeira a qual acaba por aumentar a sua inflamabilidade, resultando em queimadas "que colocam em movimento um ciclo vicioso de mortalidade de árvores, aumento da carga de combustível, reentrada do fogo e, por fim, destruição total da floresta" (FEARNSIDE, 2020). De acordo com o Instituto de Pesquisas Espaciais (INPE) e o IPAM, em 2019 foram registrados focos de incêndio 32.728 focos foram registrados no INEP, totalizando um aumento de 60\% das queimadas na Amazônia, confirmando que a ampliação está ligada ao desmatamento, já que ao derrubar a floresta para limpar o terreno com o objetivo de agropecuária ou plantações de monocultura, são os principais responsáveis pelas queimadas (IPAM, 2019). O Instituto do Homem e Meio Ambienta da Amazônia (IMAZON), em estudo levantado, detectou 1.499 quilômetros quadrados de desmatamento na Amazônia Legal em agosto de 2020, um aumento de 68\% em relação ao mesmo mês de 2019 (IMAZON, 2020), trazendo graves consequências imediatas para as aldeias indígenas locais que vivem nas proximidades e são afetados diretamente pela destruição da terra.

Destarte, é possível compreender que as ações ilícitas e descontroladas de desmatamentos e incêndios na floresta amazônica trazem imensos impactos negativos não somente para a fauna e flora, mas também para a vida humana como um todo. A destruição ambiental é responsável por deixar o ecossistema e a vida humana em considerável vulnerabilidade, já que, existe uma forte erosão do solo e a exaustão de nutrientes característicos do desmatamento seja por atividades agrícolas, queimadas, extração de minérios ou de madeira, fazendo com que haja uma grande perda da biodiversidade da fauna e da flora, afetando chuvas e, consequentemente, o abastecimento de cidades pelos reservatórios hidrelétricos já que a floresta quando está com o ar puro é responsável por chuva abundantes por todo o território brasileiro, além das queimadas florestais que provocarem a emissão de gases de efeito estufa, 
contribuindo também para as mudanças climáticas que afetam diretamente a vida humana (ABRAMOVAY, 2019).

O desmatamento combinado com as ações das queimadas e exploração da floresta, geram as mudanças no uso do solo para a criação de animais na pecuária de grande escala e outros interesses do agronegócio, os quais contribuem em níveis assustadores para o aquecimento do clima (FERNANDES, 2020), resultando na destruição em larga escala do meio ambiente e, naturalmente, da vida humana.

Vale destacar que, conforme já mencionado, o Novo Código Florestal abriu brechas para o cenário dos desmatamentos florestais se tornarem ainda mais agravantes. Porém, além de considerar a falta de segurança jurídica do código, é importante destacar que a política ambiental do atual Governo Federal, tendo como líder do Executivo Jair Bolsonaro, foram importantes para a contribuição do desmatamento e das queimadas ocorridas na floresta Amazônica. No ano de 2019 o Instituto Brasileiro do Meio Ambiente e dos Recursos Naturais Renováveis (IBAMA) identificou uma queda da aplicação das multas ligadas ao desmatamento num valor de $34 \%$, tendo sido considerado o número mais baixo dos últimos anos. A queda alarmante se deu em razão do presidente Jair Bolsonaro, ter impedido que os agentes do IBAMA destruíssem equipamentos utilizados em extração ilícita de madeiras, mesmo sendo uma prerrogativa do cargo ${ }^{7}$. Além de que, o governo, dentre tantas outras ações, uniu Ministérios do Meio Ambiente com o da Agropecuária, desmontou, desvalorizou e diminuiu orçamentos dos órgãos, levando à diminuição do número de funcionários, o que prejudica a fiscalização ambiental, além de deixar a cargo da pasta da Agropecuária a fiscalização de áreas de preservação, que muitas vezes se confunde com o interesse da bancada ruralista do Congresso brasileiro, incentivando que as áreas sejam cada vez mais desflorestadas para atender às necessidades da Agropecuária.

Ademais, o governo atual no ano de 2019 foi responsável por implementar uma medida provisória que reduz as burocracias ambientais, conhecida como MP da Liberdade Econômica, a qual determina que em os órgãos responsáveis por liberar licenças ambientais para desmatamento não o fizerem em determinado período, estará a licença concedida ${ }^{8}$, lei esta que,

\footnotetext{
7 TRIGUEIRO, André. 15 pontos para entender os rumos da desastrosa política ambiental no governo Bolsonaro. G1 Notícias, 03 de junho de 2019. Disponível em: https://g1.globo.com/natureza/blog/andretrigueiro/post/2019/06/03/15-pontos-para-entender-os-rumos-da-desastrosa-politica-ambiental-no-governobolsonaro.ghtml. Acessado em: 10 de mai.2021.

8 STOCHERO, Tahiane. Comissão denuncia Bolsonaro ao Tribunal Penal Internacional por supostamente promover ataques contra povos indígenas. G1 Notícias, 20 de novembro de 2019. Disponível em: https://g1.globo.com/sp/sao-paulo/noticia/2019/11/28/comissao-denuncia-bolsonaro-ao-tribunal-penalinternacional-por-supostamente-promover-ataques-contra-os-povos-indigenas.ghtml. Acessado em: 10 de mai.2021.
} 
inegavelmente, contribuiu para o aumento da degradação da floresta amazônica desde então. No mesmo ano o presidente editou a então conhecida MP da grilagem, a qual permite a obtenção de título sem vistoria prévia em áreas de até 1.400 hectares em alguns municípios da Amazônia e autoriza invasores que entraram em terras até dezembro de 2018 a se tornarem proprietários, com o intuito de acelerar concessão de terras. A medida caducou, no entanto, foi inspiração para um PL 510/21 a qual segue em votação na casa dos Senadores.

Outra falta de política ambiental que envolve o governo Bolsonaro é com o advento da pandemia do novo coronavírus, cujas aldeias indígenas e Comissões de Direitos Humanos manifestaram grande preocupação com a situação dos índios, haja vista que a contaminação corria rapidamente entre as aldeias em razão da continuada execução de garimpos ilegais nas terras indígenas. Outrossim, houve por parte do líder do Executivo vetos de trechos da lei $\mathrm{n}^{\circ}$ 14.021/2021 regulamenta sobre medidas de proteção social para prevenção do contágio e da disseminação da Covid-19 nos territórios indígenas, nos trechos que garantiam acesso à água potável, distribuição gratuita de material higiénico e de limpeza para as aldeias indígenas, vetou, também, que povos indígenas com quadro grave tivessem atendimento prioritário, sob a justificativa de que tais ações gerariam despesas obrigatórias ao Poder Executivo e um grande impacto orçamentário e financeiro (MENSAGEM DE VETO, 2020), confirmando que houve um total descaso do governo federal para com os povos indígenas durante a pandemia gerando graves violações de direitos humanos, a ponto de considerar às Comissões de Direitos Humanos que o atual governo perpetra, não somente um crime de genocídio, mas também um grave crime contra a humanidade, o qual nada mais é do que a agressão generalizada de forma sistêmica contra a população civil, ambos já devidamente definidos pelo Estatuto de Roma (CONECTAS, 2020).

Dessa forma, se a Constituição Federal do Brasil considera que a proteção da espécie humana depende simultaneamente do equilíbrio ecológico entre o ambiente e o homem, é, portanto, o ambiente comparado com um direito fundamental, o qual deve ser protegido e respeitado pelos Poderes Público, bem como pela sociedade que nela vive. Assim, as queimadas e os desmatamentos ocorridos nos últimos dois anos que atingem a destruição de importantes e imprescindíveis recursos naturais para a vida humana, e as omissões e a falta de política ambiental do governo brasileiro, comprometendo diretamente o ecossistema e a vida dos seres humanos.

Podem, então, os crimes contra o ambiente e o consequente impacto grave na vida da população, inclusive da população indígena, ser considerados crimes de ecocídio, já que, de acordo com o seu conceito, de destruição total de um ecossistema de um determinado território, 
logo, a destruição da floresta amazônica mediante as queimadas e desmatamentos, além de destruírem o funcionamento da floresta, impede que os seres humanos que dependam de seus recursos o aproveite de maneira efetiva, já que, conforme amplamente explicitado, a morte da biodiversidade, a erosão do solo, e a mudança climática oriundas dos crimes ambientais são responsáveis por afetar a vida humana, nos tirando o direito contido na Carta Magna de termos um ambiente ecológico equilibrado.

Necessário, seria, existir uma competência de investigação pelo TPI, de acordo com o Policy paper on case selection and prioritisation, já que os crimes de destruição ambientais ocorridos no Brasil desde o ano de 2019 até agora, deverão ter uma atenção especial pelo Tribunal Internacional por se tratarem de crimes de alta gravidade, logo, comparados com o crime contra a humanidade que é de jurisdição do TPI para julgamento. No entanto, como já salientado, tal tipificação ainda não existe, dificultando o julgamento pelo órgão e a responsabilização de agentes.

Dessa forma, entende-se que o meio ambiente ecologicamente equilibrado é direito fundamental e que a sua violação configura grave violação aos direitos humanos; portanto, o "ecocídio" poderá ser considerado uma modalidade de crimes contra a humanidade. O meio ambiente ecologicamente equilibrado preserva a manutenção da própria vida, sendo imperioso concluir que a sua violação cria riscos para a própria sobrevivência da espécie humana (GORDILHO; RAVAZZANO, p.697, 2018).

No âmbito nacional, em razão dos devastados acontecimentos ocorridos na floresta amazônica e do rompimento da barragem em Brumadinho, foi elaborado um Projeto de Lei (2019) número 2787/2019, que altera a lei de crimes ambientais para a inclusão da tipificação do crime de ecocídio. O PL em seu artigo $2^{\circ}$ dispõe que a lei de crimes ambientais passará a vigorar "Dar causa a desastre ecológico pela contaminação atmosférica, hídrica ou do solo, pela destruição significativa da flora ou mortandade de animais, que gere estado de calamidade pública. Pena reclusão de 4 a 20 anos e multa". Contudo, o PL ainda segue, desde 2019, em apreciação no Senado Federal sem qualquer prioridade e relevância pelo poder Legislativo.

\section{O PACTO ECOLÓgICO EUROPEU COMO UMA URGÊNCIA CONTRA OS CRIMES AMBIENTAIS NO BRASIL}

De tudo o quanto já foi exposto, é notória a necessidade de uma tipificação internacional e doméstica do crime de ecocídio para a responsabilização de graves crimes contra o meio ambiente e contra a humanidade, já que o ambiente é peça fundamental para a sobrevivência 
humana, a fim de tornar uma norma suficiente para barrar a destruição dos ecossistemas no Brasil. No entanto, a não tipificação do crime dificulta a responsabilização dos agentes algozes e, além disso, a medida do Policy paper on case selection and prioritisation, não possui força sozinha para impedir tais degradações, de modo que outras medidas que estão surgindo no cenário atual podem ser importantes para a proteção da vida ambiental e humana no Brasil.

Dessa maneira, trataremos neste ponto acerca de um importante instrumento internacional criado na União Europeia (UE), que tem a intenção de mudar as regras sobre a proteção ambiental de maneira a impactar muitos países. O Pacto Ecológico Europeu (PEE), ou como também conhecido European Green Deal, nada mais é do que uma estratégia lançada pela União Europeia que tem por finalidade mudar a lógica de produção tornando-a sustentável, de modo a manter e aumentar a qualidade de vida dos europeus e tornando a Europa num plano de sociedade justa e próspera através de uma eficiente utilização de recursos naturais (PARLAMENTO EUROPEU, 2020). O Pacto possui como finalidade impulsionar a utilização eficiente dos recursos através da transição para uma economia limpa e circular e restaurar a biodiversidade e reduzir a poluição. Tal acordo deverá ser regulamentado pela Lei Climática Europeia a qual transformará o compromisso político numa obrigação jurídica para todos os Estados membros, a lei que segue em análise no Parlamento Europeu.

Este Pacto possui ambições ambientais que vão além dos países Europeus. O pacto poderá ser uma arma que impactará na diminuição da prática ilegal de desmatamentos e queimadas na floresta Amazônica, influenciando na diminuição das práticas de ecocídio no território brasileiro, uma vez que lida com questões de relações comerciais entre a UE e países terceiros (BARUZZI; MANHAES; AGOSTINHO, 2020).

É cediço que o dinheiro e a economia global ainda são os elementos que norteiam as nações, dessa forma, somente um grande impacto econômico e no orçamento brasileiro seria, talvez, uma medida significante na luta contra o ecocídio que vem ocorrendo no país. E, um dos pilares mais importantes do PEE foi a criação da estratégia From farm to fork (da fazenda para o prato), cujo fim é contribuir para a neutralidade climática da União Europeia em 2050.

O From farm to fork tem como objetivo tornar o sistema alimentar da UE um padrão global de sustentabilidade, destacando a necessidade da redução do uso de antibióticos e fertilizantes na agricultura, além de envolver a produção, o transporte e a distribuição dos produtos, com a finalidade de aumentar a participação da agricultura biológica que conservam a presença da natureza e seus nutrientes, de maneira a conservar solo, água, ar, fauna, e incentivar rigorosos padrões de bem-estar animal, ou seja, os mercadores europeus não irão admitir produtos que sejam degradantes ao meio ambiente e prejudiciais à saúde humana, desde 
o seu processo inicial até o consumo final. Tal estratégia deverá ser um modelo europeu de sustentabilidade na mudança de práticas e processos produtivo não apenas nos países da UE, como para todos os países possuam relações comerciais com o Bloco Europeu (MIGUEL; PINTO; FILIPE, 2020).

A aplicação da nova estratégia From farm to fork do PEE, impactará diretamente a relação comercial entre a União Europeia e diversos países, dentre eles o Brasil, que é um dos principais clientes importadores de commodities do Brasil, pois, os países que importam comidas e mercadorias alimentícias para a União Europeia que não se sujeitarem às novas modalidades da estratégia não terão seus alimentos nos mercados europeus. Tal política de relação ambiental criada pelo PEE tende a enfraquecer posições de países como o Brasil que destroem a sua biodiversidade, uma vez que, terá que se adequar aos novos moldes de economia ambiental para atender um de seus maiores importadores.

O Pacto Ecológico Europeu expressa a convicção de que as suas ambiciosas metas ecológicas não terão resultados expressivos enquanto a Europa agir de forma isolada e inclui no acordo, portanto, mecanismos que protejam o continente de produtos degradantes ao meio ambiente, utilizando-se da tributação como meio de desestimulo (OLIVEIRA; ALVERNE, 2020), de modo que tal acordo fará com que o bloco invista no diálogo ativo com os estados parceiros, envolvendo o Brasil.

De acordo com pesquisadores, o Brasil está entre os 10 países que mais emitem $\mathrm{CO} 2$, sendo a agricultura, o desmatamento e as queimadas os principais responsáveis pelas emissões, e não bastasse tal fato, provém desses desmatamentos e queimadas, que provocam o ecocídio do ecossistema, a grande parte dos produtos brasileiros que são exportados para a Europa, de maneira que, o Brasil será fortemente pressionado para adotar as medidas impostas pelo PEE para não perder relação com uma dos seus maiores importadores de alimentos (BARUZZI; MANHAES; AGOSTINHO, 2020). Assim, se o Brasil não seguir os padrões ambientais no que toca aos produtos agrícolas e agropecuários da fronteira alimentar impostos pelo PEE, a UE não deixará de ser um de seus parceiros de comércio.

Dessa forma, a nova estratégia do PEE influenciará a economia brasileira, em razão da vasta parceria comercial entre o Brasil e o Bloco UE, de modo que irá impactar substancialmente a relação do brasil com suas atuais políticas ambientais:

O Pacto Verde, com a pretensão de reorientar todos os setores relacionados ao desenvolvimento econômico, impactará não apenas o Brasil, mas todos os estados parceiros do bloco, pois a sua ambição vai além das suas fronteiras e objetiva proteger a população europeia de produtos importados degradantes para a saúde e à natureza. Os países que detêm relações comerciais com a UE terão que se adequar aos novos pré-requisitos do bloco e deverão adotar 
políticas e medidas adequadas às exigências ambientais. O Pacto Ecológico poderá impactar diretamente na economia brasileira, dado o grande volume do comércio e o investimento privado da UE no Brasil. No ano de 2019, o total de investimentos direto no país foi de $66 \%$, proveniente da União Europeia (...). Além disso, o Bloco Europeu é o segundo maior parceiro comercial do Brasil (OLIVEIRA; ALVERNE, p.116, 2020).

Com isso, o reposicionamento a mudança nas ações de descaso com o meio ambiente ocorrido no Brasil desde os anos de 2019/2020, será fundamental para se conseguir um crescimento econômico estável e sustentável, de acordo com as regras do PEE. Os produtos brasileiros devem ser produzidos com adequação às exigências de consumidores mais conscientes sobre a poluição mundial. Este é um perfil em ascendência no Brasil e, especialmente, na Europa (OLIVEIRA; ALVERNE, 2020).

Por conseguinte, a estratégia do PEE ajudará com que o Brasil fortaleça sua bandeira de sustentabilidade e suas políticas ambientais, objetivando que as florestas brasileiras não sofram com os desmatamentos e queimadas ilegais, fazendo com que o número de ações irregulares e desumanas diminuíam, salvando a Amazônia, o ecossistema e a humanidade em geral, diminuindo, consideravelmente, as ações de ecocídio e garantindo a relação comercial entre Brasil e UE.

Recentemente, foi enviada ao Brasil uma carta elaborada pelas empresas europeias, dentre elas Tesco, J Sainsbury, Marks \& Spencer e Aldi, com a informação de que pretendem boicotar produtos brasileiros sob a justificativa de que o país está buscando a qualquer custo, aumentar o desmatamento da floresta amazônica, elaborando projetos de lei como o PL 510/21 que traz à tona o tema da MP da grilagem ${ }^{9}$. É clarividente preocupação das empresas europeias não somente no território brasileiro, mas, também, sobre o impacto que todo esse desmatamento de uma das maiores florestas mundiais pode causar no planeta, já que os crimes ambientais não têm fronteiras, a emissão de CO2 no Brasil ou em qualquer outro país, impacta em todo o globo terrestre, logo, a destruição do ecossistema da floresta amazônica é preocupante em toda a esfera internacional.

\section{CONCLUSÃO}

O presente artigo visou analisar os desmatamentos e queimadas ocorridas na floresta amazônica durante o ano de 2019, além de compreender a atuação das normas jurídicas e das

\footnotetext{
${ }^{9}$ Empresas europeias ameaçam boicotar produtos brasileiros por desmatamento, DW Notícias, 05 de maio de 2021. Disponível em: https://www.dw.com/pt-br/empresas-europeias-amea\%C3\%A7am-boicotar-produtosbrasileiros-por-desmatamento/a-57437406. Acessado em: 07 de mai. 2021.
} 
medidas públicas adotadas pelo atual governo federal e, também, a sua atuação perante as ocorrências da pandemia da Covid19, identificando como o Pacto Ecológico Europeu poderia ser uma alternativa contra crime de ecocídio ocorrido no Brasil. A partir disso, o artigo discutiu a evolução do crime de ecocídio, e como o Tribunal Penal Internacional atuou para edificar o entendimento do crime, colaborando fundadamente na produção de precedentes e possíveis tipificações, influenciando para um olhar mais atento sobre a problemática.

A pesquisa, após extensos estudos bibliográficos e estatísticos, detectou que a Constituição Federal brasileira protege o direito do ambiente como sendo um direito fundamental onde a fauna, flora e o homem devem conviver em equilíbrio e harmonia para o desenvolvimento nacional, devendo, portanto, o meio ambiente ser protegido tanto pela sociedade quanto pelo poder público. No entanto, mesmo com a guarda Constitucional e leis infraconstitucionais, o meio ambiente, sobretudo a floresta amazônica, continua sendo cada vez mais degradada, prejudicando direta e negativamente a vida humana, além dos povos indígenas que sofrem os impactos de maneira mais imediata, devendo tais destruições serem enquadradas no conceito de crime de ecocídio.

Restou demonstrado, porém, que além da falta de tipificação do crime de ecocídio no âmbito internacional ou nacional, e a atuação isolada do Policy paper on case selection and prioritisation impossibilitam a responsabilização dos indivíduos e de entidades pelo crime de ecocídio, motivo pelo qual, o artigo científico verificou que uma alternativa para uma possível diminuição dos crimes de ecocídio que vêm acontecendo no Brasil, pode ser a adoção do modelo do Pacto Ecológico Europeu, sobretudo do programa From farm to fork o qual discute a criação de uma cadeia de produção alimentar sustentável de alimentos.

Tal programa poderá afetar o Brasil diretamente, haja vista que o país possui fortes relações comerciais com a União Europeia na venda de commodites, sendo que, caso o Brasil queira continuar mantendo as relações comerciais com o bloco deverá cumprir as exigências de sustentabilidade. De modo que, o acordo da UE poderá influenciar positivamente para que o Brasil diminua ou acabe com as queimadas e os desmatamentos exagerados e ilícitos que vêm ocorrendo no terreno, combatendo, assim, o crime de ecocídio indiretamente.

Por fim, a preocupação mundial com os crimes ambientais que vêm acontecendo na floresta amazônica, em especial durante o governo Bolsonaro, podem ser, também, ferramentas auxiliadoras para que o Brasil, através da pressão externa, corrija suas políticas ambientais as quais, como já exaustivamente exposto, contribuem para o agravamento dos desmatamentos e queimadas na floresta, adotando medidas como o PEE. Tais medidas cedem às exigências que salvaguardam o ecossistema não somente europeu, mas também global, já que, o impacto de 
destruição ambiental não é restrito a apenas um país, pois todo o planeta sofre com os problemas de crise ambiental. Sendo assim, os grandes acordos ambientais mundiais podem ser uma opção para a diminuição do crime ambiental no Brasil.

Destarte, é de extrema importância, ainda, que o crime de ecocídio seja tipificado internacionalmente e nacionalmente, a fim de que os responsáveis pelos crimes contra a vida humana e ambiental sejam punidos e que tais ações sejam suficientes e efetivas para barrar com a degradação ambiental.

\section{REFERÊNCIAS}

ABRAMOVAY, Ricardo. Amazônia: por uma economia do conhecimento da natureza, São Paulo, Edições Terceira Via, Abong, Iser, 2019.

BARUZZI, Lucas; MANHAES, Jeferson; AGOSTINHO, Thiago Munhoz. Impactos do Pacto Ecológico Europeu nos setores produtivos no Brasil. Revista Eletrônica EcoDebate, Cidadania e Meio Ambiente. Portal EcoDebate, 2020. Disponível em: https://www.ecodebate.com.br/2020/08/07/impactos-do-pacto-ecologico-europeu-nos-setoresprodutivos-no-brasil/. Acesso em 10 de mai. 2021.

BRASIL. Constituição (1988). Constituição da República Federativa do Brasil. Brasília, DF: Senado Federal, 1988.

BRASIL. Decreto $\mathbf{n}^{\mathbf{0}} 4.388$ de 2002. Promulga o Estatuto de Roma do Tribunal Penal Internacional- Brasil: Congresso Nacional, 2002. Disponível em: http://www.planalto.gov.br/ccivil_03/decreto/2002/d4388.htm. Acesso em: 12 de mar. 2021.

BRASIL. Lei $\mathbf{n}^{\mathbf{0}}$ 12.651, de 25 de maio de 2012. Dispõe sobre a proteção da vegetação nativa; altera as Leis $n^{\circ}$ s 6.938, de 31 de agosto de 1981, 9.393, de 19 de dezembro de 1996, e 11.428, de 22 de dezembro de 2006; revoga as Leis ${ }^{\circ}$ s 4.771, de 15 de setembro de 1965, e 7.754, de 14 de abril de 1989, e a Medida Provisória n 2.166-67, de 24 de agosto de 2001; e dá outras providências. Brasil: Congresso Nacional, 2012. Disponível em: http://www.planalto.gov.br/ccivil_03/_ato2011-2014/2012/lei/112651.htm. Acesso em: 27 de mar.2021.

CIDH aponta que povos Yanomami e Ye'kwana estão em situação grave no Brasil. Conectas Direitos Humanos, 2020. Notícias. Disponível em https://www.conectas.org/noticias/cidhaponta-que-povos-yanomami-e-yekwana-estao-em-situacao-grave-no-brasil/.Acesso em: 15 de mar. 2021.

Empresas europeias ameaçam boicotar produtos brasileiros por desmatamento, DW Notícias, 05 de maio de 2021. Disponível em: https://www.dw.com/pt-br/empresas-europeiasamea\%C3\%A7am-boicotar-produtos-brasileiros-por-desmatamento/a-57437406. Acessado em: 07 de mai. 2021.

FEARNSIDE, P.M. Destruição e Conservação da Floresta Amazônica, vol., 1, Manaus, Editora do INPA, p.11, 2020. 
FERNANDES, Sabrina. Se quiser mudar o mundo: um guia político para quem se importa, [livro eletrônico]. São Paulo, Planeta, 2020.

FIORILlO, Celso Antonio Pacheco; CONTE, Christiany Pegorari. Crimes Ambientais, São Paulo, Saraiva, 2012.p.20.

GORDILHO, H.; RAVAZZANO, F. (2018). Ecocídio e o Tribunal Penal $\begin{array}{lllll}\text { Internacional. Revista Justiça Do } & \text { Direito, 31(3), } & \text { 688-704. }\end{array}$ https://doi.org/10.5335/rjd.v31i3.7841

HIGGINS, Polly. Earth is our business: changing the rules of the game. $1^{\text {a }}$ edição. Londres: Shepheard-Walwyn, 2012.

IMAZON. Sistema de Alerta de Desmatamento agosto de 2020. Brasil. Disponível em: https://imazon.org.br/wp-content/uploads/2020/09/SAD-agosto-2020.pdf. Acesso em: 27 de mai.2021.

INTERNATIONAL CRIMINAL COURT. ICC Prosecutor, Fatou Bensouda, publishes comprehensive Policy Paper on Case Selection and Prioritisation, 25 de set. 2016. Disponível em: https://www.icc-cpi.int/Pages/item.aspx?name=pr1238. Acesso em: 20 de mai.2021.

MARTIN-CHENUT, Kathia; NEYRET, Laurent; PERRUSO, Camila. Rumo à internacionalização da proteção penal do meio ambiente: dos ecocrimes ao ecocídio. Revista de Direito Internacional, Brasília, v. 12, n. 2, 2015.

MENSAGEM DE VETO N ${ }^{\circ} 378$. Lei no 14.021, de 7 de julho de 2020. Dispõe sobre medidas de proteção social para prevenção do contágio e da disseminação da Covid-19 nos territórios indígenas; cria o Plano Emergencial para Enfrentamento à Covid-19 nos territórios indígenas; estipula medidas de apoio às comunidades quilombolas, aos pescadores artesanais e aos demais povos e comunidades tradicionais para o enfrentamento à Covid-19; e altera a Lei $\mathrm{n}^{\circ}$ 8.080, de 19 de setembro de 1990, a fim de assegurar aporte de recursos adicionais nas situações emergenciais e de calamidade pública. Brasil: Câmara Legislativa. Disponível em: https://www2.camara.leg.br/legin/fed/lei/2020/lei-14021-7-julho-2020-790392-veto-161012pl.html. Acessado em: 05 de mar. 2021.

MIGUEL, José; PINTO, Lucinda; FILIPE, Cláudia. Pacto Verde Europeu: A estratégia "do prado ao prato". InforCNA, Portugal, p.1-16, jul de 2020. Disponível em: http://inforcna.pt/post/pacto-verde-europeu-a-estrategia-do-prado-ao-prato/1384. Acessado em: 27 de mai. 2021.

MISTURA, Alessandra. Is there space for environmental crimes under international criminal law? The impact of the office of the prosecutor policy paper on case selection and prioritization on the current legal framework. Columbia Journal of Environmental Law, v. 43 n. 1, 2019. Disponível em: https://journals.library.columbia.edu/index.php/cjel/article/view/3740. Acessado em: 21 de mai. 2021.

OLIVEIRA, Sócrates; ALVERNE, Tarin Cristino Frota Mont’. O pacto verde europeu na liderança pelo desenvolvimento sustentável: uma análise dos potenciais reflexos da tributação ambiental para a geração de energia solar no Brasil. In: Denise Lucena Cavalcante; Juarez 
Freitas; Paulo Caliendo (Orgs.). Reflexos da Tributação Ambiental no âmbito da energia solar [recurso eletrônico] -- Porto Alegre, RS: Editora Fi, 2020. p. 313.

PRADO, Luiz Redis. Direito penal do ambiente: crimes ambientais (Lei 9.605/1998), 7 . $^{\text {a }}$ ed., Rio de Janeiro: Forense, 2019.

PROJETO DE LEI. Projeto de Lei $\mathbf{n}^{\mathbf{0}}$ 2787, de 22 de outubro de 2019. Altera a Projeto de Lei Número 2787/2019, Altera a Lei n ${ }^{\circ}$ 9.605, de 12 de fevereiro de 1998 (Lei de Crimes Ambientais), para tipificar o crime de ecocídio e a conduta delitiva do responsável por desastre relativo a rompimento de barragem, e dá outras providências. Brasil: Câmara Legislativa. Disponível em: https://www.camara.leg.br/proposicoesWeb/prop_mostrarintegra;jsessionid=node01i9pftkbk3 jtf18dojtqf31wia2269354. node0?codteor $=1744716 \&$ filename $=P L+2787 / 2019$. Acessado em: 12 de mai. 2021.

PARLAMENTO EUROPEU. Proposta de Resolução do Parlamento Europeu sobre o Pacto Ecológico Europeu ((2019/2956(RSP)). União Europeia, 10 de jan. 2020. Disponível em: https://www.europarl.europa.eu/doceo/document/B-9-2020-0042_PT.html. Acessado em: 27 de mai. 2021.

Queimadas na Amazônia em 2019 seguem o rastro do desmatamento. IPAM Amazônia, 20 de agosto de 2019. Disponível em: https://ipam.org.br/queimadas-na-amazonia-em-2019-seguemo-rastro-do-desmatamento/. Acesso em: 27 mar. 2021.

RODRIGUES, Marcelo Abelha. Direito ambiental esquematizado. 5. a ed., São Paulo, Saraiva Educação, 2018. p.63.

STOCHERO, Tahiane. Comissão denuncia Bolsonaro ao Tribunal Penal Internacional por supostamente promover ataques contra povos indígenas. G1 Notícias, 20 de novembro de 2019. Disponível em: https://g1.globo.com/sp/sao-paulo/noticia/2019/11/28/comissao-denunciabolsonaro-ao-tribunal-penal-internacional-por-supostamente-promover-ataques-contra-ospovos-indigenas.ghtml. Acessado em: 10 de mai.2021.

TRIGUEIRO, André. 15 pontos para entender os rumos da desastrosa política ambiental no governo Bolsonaro. G1 Notícias, 03 de junho de 2019. Disponível em: https://g1.globo.com/natureza/blog/andre-trigueiro/post/2019/06/03/15-pontos-para-entenderos-rumos-da-desastrosa-politica-ambiental-no-governo-bolsonaro.ghtml. Acessado em: 10 de mai.2021.

35\% do desmatamento da Amazônia é grilagem, indica análise do IPAM. IPAM Amazônia, 20 de novembro de 2019. Disponível em: https://ipam.org.br/35-do-desmatamento-naamazonia-e-grilagem-indica-analise-do-ipam/. Acesso em: 25 de jun. 2021. 